\title{
The Effect of Resveratrol on the Quality of Extended Boar Semen During Storage at $17^{\circ} \mathrm{C}$
}

\author{
David Martin-Hidalgo ${ }^{1}$, Ana Hurtado de Llera ${ }^{1}$, Heiko Henning ${ }^{2}$, Ulrike Wallner ${ }^{2}$, Dagmar Waberski ${ }^{2}$, \\ Maria J. Bragado ${ }^{1}$, Maria C. Gil ${ }^{1 *} \&$ Luis J. Garcia-Marin ${ }^{1 *}$ \\ ${ }^{1}$ Research Group of Intracellular Signalling and Technology of Reproduction (SINTREP), Veterinary School, \\ University of Extremadura, 10003 Caceres, Spain \\ ${ }^{2}$ Unit for Reproductive Medicine of Clinics, Clinic for Pigs and Small Ruminants, University of Veterinary \\ Medicine, Foundation, Hannover, Germany \\ Correspondence: Luis J. Garcia-Marin, Research Group of Intracellular Signalling and Technology of \\ Reproduction (SINTREP), Veterinary School, University of Extremadura, 10003 Caceres, Spain. Tel: \\ 34-927-257-100 ext. 51327. E-mail: ljgarcia@unex.es \\ *Both authors contributed equally as senior investigators of this study.
}

Received: May 29, 2013 Accepted: June 20, 2013 Online Published: July 15, 2013

doi:10.5539/jas.v5n8p231 URL: http://dx.doi.org/10.5539/jas.v5n8p231

\begin{abstract}
The natural polyphenol resveratrol may be beneficial to many aspects of cell function and animal health, although its actions in the male reproductive system vary depending on animal species. This work investigates resveratrol effects on the quality of preserved boar semen during liquid storage at $17^{\circ} \mathrm{C}$. We used three approaches: 1) evaluation of conventional parameters of seminal quality, 2) measurement of specific response to capacitating stimuli, and 3) evaluation of mitochondria membrane potential and ATP content. Resveratrol supplementation causes i) a loss in the response of liquid stored boar spermatozoa to capacitating stimuli, ii) a decrease in the sperm ATP content and iii) a reduction in the mitochondrial membrane potential. Moreover, higher concentrations of resveratrol increase plasma membrane phospholipid disorder and reduce the percentage of motile spermatozoa. These results suggest that semen doses supplemented with resveratrol could be considered sub-fertile compared with semen stored hypothermically in standard conditions.
\end{abstract}

Keywords: resveratrol, boar semen storage, calcium influx, ATP

\section{Introduction}

Nowadays in the worldwide pig production, artificial insemination (AI) is made with semen that has been extended in the liquid state and stored at $15-20^{\circ} \mathrm{C}$ for 1 to 5 days (Johnson et al., 2000). AI allows a better distribution of genetic material of high quality and minimizes boar transportation. To preserve spermatozoa for prolonged periods, their metabolic activity needs to be reduced and this is approached by semen dilution into an appropriate medium and by lowering the temperature. Several commercial boar extenders have been proposed with this objective (Gadea, 2003), although the most widely used extender is the Beltsville-Thawing Solution (BTS) developed by Pursel and Johnson (1975) for thawing boar spermatozoa frozen in the pellet form, and later adapted for liquid storage (Pursel et al., 1978). Sperm membrane is rich in polyunsaturated fatty acid, which makes them very susceptible to oxygen-induced damage mediated by lipid peroxidation (LPO), especially in boar spermatozoa, which contains a high concentration of polyunsaturated fatty acids (Awda et al., 2009; Waterhouse et al., 2004). Several antioxidants have been used successfully in the supplementation of boars extenders: superoxide dismutase and catalase (Roca et al., 2005), $\alpha$-tocopherol (Cerolini et al., 2000) and L-Glutamine (Funahashi \& Sano, 2005).

Resveratrol (RSV) is a natural grape-derived polyphenolic phytoalexin that possesses pleiotropic effects including anticancer, anti-aging, anti-inflammatory and anti-oxidant actions, as well as cardioprotection and neuroprotection (Fulda et al., 2010; Pervaiz \& Holme, 2009). RSV effectively scavenges superoxide and peroxynitrite radicals generated from enzymatic and non-enzymatic systems, and afford protection against DNA damage caused by reactive oxygen species (ROS) in somatic cells (K. W. Lee \& H. J. Lee, 2006).

Effects of resveratrol in spermatozoa have been studied in recent works. Thus, RSV addition $(0.1,1.0$ and 10.0 $\mathrm{mM}$ ) to cryopreservation medium of human spermatozoa is able to prevent cryopreservation-induced lipid 
damage (Garcez et al., 2010) and at $10 \mathrm{mM}$ also the cryopreservation-induced DNA damage (Branco et al., 2010). Although in both studies RSV treatment is not able to prevent the observed reduction in sperm motility after thawing, they conclude that this polyphenol might be used for the process of cryopreservation of human spermatozoa, at least for intracytoplasmic sperm injection (ICSI) where motile spermatozoa are not needed to achieve fertilization.

In a different specie, ram, the use of RSV in the cryopreservation medium causes a decrease in the mitochondrial membrane potential without any effects in spermatozoa motility, or the integrity of acrosome or plasma membrane (Silva et al., 2012).

Collodel et al. (2011) describe that $100 \mu \mathrm{M}$ resveratrol treatment leads to a loss in viability in human spermatozoa as well as in rat spermatocytes, although at $15 \mu \mathrm{M}$ has a protector effect against ROS.

Resveratrol has been also studied as an antioxidant added to the diet of rats (Juan et al., 2005), where results are beneficial. The lower diameter of seminiferous tubules together with an increase in the density of testicular tubules produces an increase in the spermatogenic tissue would explain the increase in the spermatozoa concentration observed in rats supplemented with $20 \mathrm{mg} / \mathrm{Kg}$ resveratrol in their diets.

A recent investigation showed that intraperitoneal administration of resveratrol to rats prevents the loss of sperm motility, leads to a decrease in lipid peroxidation and prevents against oxidative stress occurring in rats with hyperthyroidism (Ourique et al., 2013).

Based on the beneficial effects of RSV in different species, the objective of the present work is to study the use of resveratrol to improve the storage of boar seminal doses at $17^{\circ} \mathrm{C}$. Therefore, we have used different experimental approaches: 1) Evaluation of conventional sperm parameters to evaluate quality of seminal doses; 2) Evaluation of calcium influx and the specific sperm response to bicarbonate as proposed by Harrison et al. (1993), and 3) Analysis of resveratrol effects on sperm mitochondria membrane potential and ATP concentration.

\section{Materials and Methods:}

\subsection{General Experiments Design}

\subsubsection{Experimental Design 1}

A total of 12 ejaculates (6 males, 2 ejaculates each) were diluted in BTS at final concentration of $35 \times 10^{6}$ spermatozoa/mL and subsequently analyzed (day 0 ). Semen samples were treated without or with different concentrations of resveratrol: $10,33,66$ and $100 \mu \mathrm{M}$ or DMSO $(0.14 \%)$ and preserved at $17^{\circ} \mathrm{C}$ for several days. Motility parameters as well as flow cytometry analyzed parameters (sperm viability, plasma membrane phospholipid disorder, acrosome membrane integrity and mitochondrial membrane potential) were analyzed at days 1,4 and 7 of preservation.

\subsubsection{Experimental Design 2}

This experiment is aimed to analyze the calcium influx kinetics and specific response to capacitating conditions in spermatozoa stored at $17^{\circ} \mathrm{C}$ in BTS without or with RSV at days 1,4 , and 7 of storage. A total of 8 ejaculates $(\mathrm{n}=8)$ from 8 different animals were diluted in BTS at final concentration of $20 \times 10^{6}$ spermatozoa $/ \mathrm{mL}$ and 33 and $100 \mu \mathrm{M}$ RSV were added. The specific response to bicarbonate under capacitating conditions in vitro was assessed by monitoring the plasma membrane integrity and intracellular calcium concentrations after incubation of spermatozoa for 3 and 60 min.

\subsection{Chemicals and Sources}

Beltsville-Thawing Solution was obtained from Minitüb GmbH (Tiefenbach, Germany). Live/dead spermatozoa viability kit including both propidium iodide (PI) and SYBR-14 probes, M540 and YoPro-1 probes were purchased from Molecular Probes (Leiden, The Netherlands). Resveratrol (3,4',5-Trihydroxy-trans-stilbene), ATP kit (FL-AA), phosphatase inhibitor cocktail 2 (P5726) and FITC-PNA were from Sigma-Aldrich ${ }^{\circledR}$ (St Louis, MI, USA); coulter isoton II diluent was from Beckman Coulter Inc. (Brea, CA, USA). JC-1 (5,5',6,6'-tetrachloro-1,1',3,3'tetraethylbenzymidazolyl carbocyanine iodine) probe was purchased from Life Technologies Ltd (Grand Island, NY, USA), Fluo-3/AM from Axxora (Lörrach, Germany), 96 well plates (clear bottom, no. 655088) from Greiner bio-one, and Percoll ${ }^{\circledR}$-saline from GE Healthcare (Munich, Germany). The rest of the chemicals were purchased from Merck (Darmstadt, Germany) and Roth (Karlsruhe, Germany).

\subsection{Animals, Sample Collection and Semen Preparation}

Fourteen boars (Duroc, Pietrain and German Large White breed, 2-4 years of age) housed at a commercial insemination station (Tecnogenext, S.L (Spain)) and at the Unit for Reproductive Medicine of Clinics 
(University of Veterinary Medicine Hannover, Germany) were used as ejaculate donors. Artificial insemination using liquid preserved semen from these boars demonstrated their fertility. Fresh ejaculates were collected with the gloved hand technique and immediately placed in a water bath at $37^{\circ} \mathrm{C}$. After collection, a computer-assisted sperm analysis system (CASA) (ISAS Psus ${ }^{\circledR}$, Proiser R+D S.L., Paterna, Valencia) was used for the evaluation of sperm concentration and motility. Morphology was evaluated by eosin-nigrosin staining, a total of 200 spermatozoa per ejaculate were evaluated by oil immersion microscopy objective 100X. Only ejaculates with at least $80 \%$ morphologically normal spermatozoa, $70 \%$ motile spermatozoa and a total number of spermatozoa higher than $10 \times 10^{9}$ were used. Immediately after collection, sub-samples of each ejaculate were diluted in BTS extender (Minitüb GmbH, Germany) and treated as follows: a) supplementation with different concentrations of resveratrol (70 $\mathrm{mM}$ stock solution in dimethyl sulfoxide, DMSO), b) addition of the highest DMSO concentration $(0.14 \%)$ used to supplement resveratrol, and c) untreated sub-sample (BTS). Sperm sub-samples were cooled at room temperature for $1.5 \mathrm{~h}$ and subsequently stored in a refrigerated incubator (FOC $225 \mathrm{I}$, VELP Scientifica, Usmate, Italy) at $17^{\circ} \mathrm{C}$ in sealed containers excluding air, in an anaerobic medium, for seven days.

\subsection{Assessment of Spermatozoa Motility}

Prior to motility analysis, seminal doses $(500 \mu \mathrm{L})$ were incubated for $40 \mathrm{~min}$ with $5 \% \mathrm{CO}_{2}$ at $38.5^{\circ} \mathrm{C}$ (Mini Galaxy A, RS Biotech, United Kingdom). After gentle mixing, semen was examined for motility pattern using a CASA system (ISAS ${ }^{\circledR}$ program, Proiser R $+D$, Paterna, Valencia, Spain) following the manufacture's guidelines. A total of $2 \mu \mathrm{L}$ of sample were placed in a pre-warmed counting chamber (Leja ${ }^{\circledR}$, Nieuw-Vennep. The Netherlands). At least 300 spermatozoa per sample were analyzed and the following sperm motility parameters were recorded: total motile spermatozoa (percentage of spermatozoa with an average path velocity $>10 \mu \mathrm{M} / \mathrm{s}$ ), progressive motile spermatozoa (percentage of spermatozoa with a straightness coefficient $>80 \%$ ), VCL (curvilinear velocity in $\mu \mathrm{M} / \mathrm{s}$ ), VSL (straight-line velocity in $\mu \mathrm{M} / \mathrm{s}$ ), VAP (average path velocity in $\mu \mathrm{M} / \mathrm{s}$ ), LIN (linearity coefficient in \%) and STR (straightness coefficient in \%).

Examinations at the University for Veterinary Medicine in Hannover were carried out with SpermVision ${ }^{\circledR}$ program as described in Henning et al. (2012). A 0.63 camera adapter (U-PMTVC tv-0.63, Olympus, Hamburg, Germany) was used.

\subsection{Flow Cytometry Analysis}

In experiment one, a Coulter EPIC XL flow cytometer (Beckman Coulter Ltd.) was used to evaluate sperm viability, plasma membrane phospholipid disorder, acrosome membrane integrity and mitochondrial membrane potential and data were analyzed using a FACStation ${ }^{\mathrm{TM}}$ and EXPOTM 32 ADC software (Beckman Coulter, Inc.). Fluorophores were excited by a $15 \mathrm{~mW}$ argon ion laser operating at $488 \mathrm{~nm}$. A total of 10,000 gated events (bases on the forward scatter and side scatter of the sperm population recorded in the linear mode) were collected per sample with a sample running rate of approximately 500 events/sec. Fluorescence data were collected in the logarithmic mode.

In experiment two, a DAKO Galaxy flow cytometer (DAKO, Hamburg, Germany) controlled by FloMax software (version 2.4, Partec, Münster, Germany) was used for intracellular calcium analysis (Hoechst 33342, PI, Fluo-3) and assessment of plasma and acrosomal membrane integrity (Hoechst 33342, PI, FITC-PNA). The cells were excited at two spots while passing the cuvette: first at a wavelength of $488 \mathrm{~nm}$ (argon ion laser; $20 \mathrm{~mW}$ ) and second at a wavelength of $365 \mathrm{~nm}$ (mercury lamp; $100 \mathrm{~W}$ ). Fluorescence signals were detected using a $455 / 10$ band pass filter (Hoechst 33342), a 537.5/22.5 nm bandpass filter (Fluo-3, FITC-PNA), and a $630 \mathrm{~nm}$ long pass filter (PI). A logical gate was used to identify the sperm population based on positive staining for Hoechst 33342 (DNA-containing events) and on being in the expected size range for spermatozoa in the forward scatter distribution. A total of 10,000 events fitting the definition of the logical gate were counted. The overlap of spectra between PI and Fluo-3 or FITC-PNA was compensated post acquisition.

\subsection{Assessment of Spermatozoa Viability}

As described previously (Martin-Hidalgo et al., 2011), fluorescent staining using the LIVE/DEAD Sperm Viability Kit was performed to assess porcine spermatozoa viability. Briefly, $100 \mu \mathrm{L}$ of liquid preserved semen $\left(35 \times 10^{6}\right.$ cells $/ \mathrm{mL}$ ) was diluted with $400 \mu \mathrm{L}$ isotonic buffer (coulter isoton II). $5 \mu \mathrm{L}$ of SYBR-14 (2 $\mu \mathrm{M}$ final concentration) and $10 \mu \mathrm{L}$ of propidium iodide ( $5 \mu \mathrm{M}$ final concentration) were added to $500 \mu \mathrm{L}$ of the diluted sample and incubated for $20 \mathrm{~min}$ at room temperature in the darkness. After incubation, cells were analyzed by flow cytometry and the percentage of viable spermatozoa (SYBR14-positive and PI-negative) was recorded. 


\subsection{Assessment of Spermatozoa Plasma Membrane Phospholipid Disorder}

Changes in membrane phospholipid disorder were assessed by using a merocyanine 540 (M540) and YoPro-1 double staining. Aliquots of $100 \mu \mathrm{L}$ of each semen sample $\left(35 \times 10^{6}\right.$ cells $\left./ \mathrm{mL}\right)$ were diluted in $400 \mu \mathrm{L}$ of isotonic buffered diluent containing $2 \mu \mathrm{L}$ of YoPro- $1\left(0.08 \mu \mathrm{M}\right.$ final concentration), then mixed and incubated at $38^{\circ} \mathrm{C}$ for $15 \mathrm{~min}$. Just before analysis, $2 \mu \mathrm{L}$ of M540 (4 $\mu \mathrm{M}$ final concentration) was added to each sample and incubated for $2 \mathrm{~min}$ and mixed before flow cytometry analysis. Labeled spermatozoa were categorized as (1) viable cells with low plasma membrane phospholipid disorder (YoPro-1 ${ }^{-1}$ M540 $)$; (2) viable cells with high plasma membrane phospholipid disorder (YoPro- $\left.1^{-} / \mathrm{M}^{2} 40^{+}\right)$; or (3) non-viable cells with altered permeability of the plasma membrane (Yo-Pro- $1^{+}$).

\subsection{Assessment of Spermatozoa Acrosome Integrity}

The acrosomal status of spermatozoa was assessed after staining the spermatozoa with fluorescein-isothiocyanate conjugated peanut agglutinin (PNA-FITC), as a marker for acrosome status, and PI. Aliquots of $100 \mu \mathrm{L}$ of each semen sample $\left(35 \times 10^{6}\right.$ cells $\left./ \mathrm{mL}\right)$ were incubated at room temperature in the dark for $5 \mathrm{~min}$ with $5 \mu \mathrm{L}$ of PNA-FITC stock solution ( $3 \mu \mathrm{g} / \mathrm{mL}$ in DMSO) and $5 \mu \mathrm{L}$ of PI ( $6 \mu \mathrm{M}$ final concentration) Just before flow cytometry analysis, $400 \mu \mathrm{L}$ of isotonic buffered diluent was added to each sample. Cells were analyzed and the percentage of live spermatozoa with damaged or reacted acrosome (PI-negative and PNA-positive spermatozoa) was recorded.

\subsection{Assessment of Spermatozoa Mitochondrial Membrane Potential}

Mitochondrial membrane potential variations were evaluated using the probe JC-1. This lipophilic cationic fluorochrome JC-1 is present as protomeric aggregates in mitochondria with high membrane potential and emits light in the orange spectrum $(590 \mathrm{~nm})$ when excited at $488 \mathrm{~nm}$. In mitochondria with low membrane potential, $\mathrm{JC}-1$ is present as monomers that emit light in the green spectrum $(525 \mathrm{~nm})$. From each sperm sample, $100 \mu \mathrm{L}$ $\left(35 \times 10^{6}\right.$ cells $\left./ \mathrm{mL}\right)$ were diluted in $400 \mu \mathrm{L}$ of isotonic buffered diluent containing $3 \mu \mathrm{L}$ of JC-1 (1 $\mu \mathrm{M}$ final concentration) and then mixed and incubated at $38^{\circ} \mathrm{C}$ for $30 \mathrm{~min}$. The samples were mixed before flow cytometry analysis. The percentage of orange stained cells, which represents the population of male germ cells with high mitochondrial membrane potential (hMMP), was recorded.

\subsection{Assessment of Calcium Influx in Spermatozoa}

Calcium influx and the specific response to bicarbonate in liquid preserved boar spermatozoa were assessed as described in Henning et al. (2012) with minor modifications. Three types of a Tyrode's medium were used for exposing spermatozoa to capacitating or non-capacitating conditions. The complete Tyrode's medium or TyrBicCa consisted of $96 \mathrm{mM} \mathrm{NaCl}, 20 \mathrm{mM}$ HEPES, $5 \mathrm{mM}$ glucose, $3.1 \mathrm{mM} \mathrm{KCl}, 0.4 \mathrm{mM} \mathrm{MgSO} \mathrm{m}_{4}, 0.3 \mathrm{mM}$ $\mathrm{KH}_{2} \mathrm{PO}_{4}, 100 \mu \mathrm{g} / \mathrm{mL}$ gentamycin sulfate (SERVA, Heidelberg, Germany), $20 \mu \mathrm{g} / \mathrm{mL}$ phenol red, $1.0 \mathrm{mM}$ sodium pyruvate, $21.7 \mathrm{mM}$ sodium lactate, $3 \mathrm{mg} / \mathrm{mL}$ bovine serum albumin (Cohn's fraction $\mathrm{V}$, fatty acid free), $15 \mathrm{mM} \mathrm{NaHCO}_{3}$ and $2 \mathrm{mM} \mathrm{CaCl}_{2}$. In the non-capacitating control media, either bicarbonate (TyrCa) or both, bicarbonate and $\mathrm{CaCl}_{2}$ (TyrControl), were omitted. In TyrControl $1 \mathrm{mM} \mathrm{Na}_{2}$-EGTA (disodium ethylene glycol tetracetate) was added. All media were adjusted to a $\mathrm{pH}$ of 7.4 at $38^{\circ} \mathrm{C}$ and an osmolality of $300 \pm 5 \mathrm{mOsmol} / \mathrm{kg}$. For equilibration, TyrBicCa was kept in an incubator $\left(38^{\circ} \mathrm{C}\right)$ under $5 \% \mathrm{CO}_{2}$ and $100 \%$ humidity, whereas $\mathrm{TyrCa}$ and TyrControl were kept sealed in a heating cabinet $\left(38^{\circ} \mathrm{C}\right)$.

Spermatozoa were prepared by adding $2 \mu \mathrm{L}$ of a Fluo-3/AM stock solution ( $1 \mathrm{mM}$ in DMSO) to $2 \mathrm{~mL}$ of sperm suspensions $\left(20 \times 10^{6}\right.$ spermatozoa $\left./ \mathrm{mL}\right)$ and incubated in the dark at room temperature. After $30 \mathrm{~min}$, spermatozoa were centrifuged through a discontinuous gradient of 35 and $70 \%$ iso-osmotic Percoll ${ }^{\circledR}$ saline essentially as described by Harrison et al. (1993). Spermatozoa were layered over a two-step gradient of $4 \mathrm{~mL}$ of $35 \%$ Percoll-saline on $2 \mathrm{~mL}$ of $70 \%$ Percoll-saline. Tubes were centrifuged at $300 \mathrm{~g}$ for $10 \mathrm{~min}$ followed by 15 $\min$ at $750 \mathrm{~g}$. After centrifugation, the supernatant was aspirated and sperm pellet was resuspended in TyrControl without RSV and BSA. The suspension of Fluo-3 loaded and washed sperm was kept in the dark at ambient temperature and used within $30 \mathrm{~min}$ of preparation. Aliquots of $5 \mu \mathrm{L}$ of Fluo-3-loaded sperm were diluted in $995 \mu \mathrm{L}$ of TyrBicCa, TyrCa or TyrControl medium without RSV added and supplemented with PI (final concentration $2.5 \mu \mathrm{g} / \mathrm{mL}$ ) and Hoechst 33342 (final concentration $0.75 \mu \mathrm{g} / \mathrm{mL}$ ). Samples were analyzed after 3 and $60 \mathrm{~min}$ on the DAKO Galaxy flow cytometer. Signals for PI distinguished between death cells with defective plasma membranes (PI-positive) and live cells with intact plasma membranes (PI-negative), whereas Fluo-3 signal subdivided the PI-negative spermatozoa population into cells with a low Fluo-3 fluorescence signal (live, low-Ca ${ }^{2+}$ sperm cells; Fluo-3-negative) and those with a higher Fluo-3 fluorescence signal (live, high-Ca ${ }^{2+}$ sperm cells; Fluo-3-positive). The change in the amount of a spermatozoa subpopulation between 3 and 60 min of incubation in TyrBicCa, TyrCa or TyrControl medium indicates the responsiveness of a sperm sample to 
capacitating conditions (Henning et al., 2012; Schmid et al., 2013). Responsiveness was calculated as changes in the live, low- $\mathrm{Ca}^{2+}$ subpopulation (PI-negative/ Fluo-3-negative; $\Delta=60 \mathrm{~min}-3 \mathrm{~min}$ ). The specific response to bicarbonate upon exposure of spermatozoa to capacitating conditions was calculated as the difference in the responsiveness to incubation conditions in TyrBicCa $(\Delta 60-3)$ and TyrCa $(\Delta 60-3)$ as described in Schmid et al. (2013).

\subsection{Quantification of ATP Spermatozoa Content}

ATP content of spermatozoa was quantified at storage temperature as well as after incubation at $38^{\circ} \mathrm{C}$. The assessments were done according to Long and Guthrie (2006) with minor modifications. Immediately after removal from the refrigerated incubator, a total of $100 \mu \mathrm{L}$ of stored semen $\left(20 \times 10^{6}\right.$ spermatozoa $\left./ \mathrm{mL}\right)$ was mixed with $1 \mu \mathrm{L}$ of phosphatase inhibitors. Another $100 \mu \mathrm{L}$ of stored semen were incubated with $5 \% \mathrm{CO}_{2}$ at $38.5^{\circ} \mathrm{C}$ for $40 \mathrm{~min}$ and then $1 \mu \mathrm{L}$ of phosphatase inhibitors was added. After $30 \mathrm{~min}$ incubation with inhibitor at room temperature, spermatozoa were frozen and stored at $-20^{\circ} \mathrm{C}$. For ATP extraction, samples were boiled for $10 \mathrm{~min}$ with $900 \mu \mathrm{L}$ of boiling buffer ( $50 \mathrm{mM}$ Tricine, $10 \mathrm{mM} \mathrm{MgSO}_{4}, 2 \mathrm{mM}$ EDTA, $\mathrm{pH}=7.8$ ) and then chilled on ice for $10 \mathrm{~min}$ and centrifuged at $5,000 \mathrm{~g}$ for $30 \mathrm{~min}$ at $4{ }^{\circ} \mathrm{C}$. ATP content was measured in $25 \mu \mathrm{L}$ of the supernatant using the ATP bioluminescent assay kit (FL-AA) from Sigma-Aldrich ${ }^{\circledR}$ following the manufacturer's guidelines. The 96 well microtiter plates were measured in a SpectraFluor Plus plate reader (Tecan Group Ltd., Maennedorf, Switzerland).

\subsection{Statistical Analysis}

A power analysis was conducted to determine the appropriate number of animals and samples. The mean and standard error of the mean were calculated for descriptive analysis. Q-Q plots were used to check for departures from the normal distribution. All the sperm variables satisfied the normality requirement for a parametric analysis of variance.

The effects of treatment (untreated and Resveratrol) and storage time (1, 4 and 7 days) on several seminal characteristics (motility, ATP content, viability, plasma membrane phospholipid disorder, acrosomal membrane integrity, mitochondrial membrane status and intracellular calcium content) were analyzed statistically using a General Linear Model, mixed-effects model (with boars and ejaculates within boars as random effects and treatment and storage time as fixed effects) was applied to the experimental design. Bonferroni's test was used to perform post hoc tests. The Pearson's correlation test was used to study the correlation among the quantity of ATP with different motility parameters (percentage of motile spermatozoa, VCL, VAP and VSL) and resveratrol concentration used. All analyses were performed using SPSS v15.0 for Windows software (SPSS Inc. Chicago, IL). The level of significance was set at $p<0.05$, except for the study of correlation where the level of significance was set at $\mathrm{p}<0.01$.

\section{Results}

In this work, the possible effect of solvent DMSO $(0.14 \%)$ was tested for all investigated parameters and no effect was observed compared with semen stored in BTS alone (data not shown).

\subsection{Effect of Resveratrol on Spermatozoa Motility During Boar Semen Storage at $17^{\circ} \mathrm{C}$ in BTS}

To evaluate the effect of RSV in spermatozoa motility parameters during semen storage, boar seminal doses were diluted in BTS without or with different concentrations of RSV $(10,33,66$ and $100 \mu \mathrm{M})$. After BTS dilution (day 0 ) and after 1,4 and 7 days of storage at $17^{\circ} \mathrm{C}$, seminal doses were incubated with $5 \% \mathrm{CO}_{2}$ at $38.5^{\circ} \mathrm{C}$ during 40 min to ensure motility and then motility parameters were evaluated (experimental design 1).

At low doses (10 and $33 \mu \mathrm{M})$ RSV addition was without effect in the percentage of motile spermatozoa (Table 1). However, addition of higher doses of RSV $(66$ and $100 \mu \mathrm{M})$ caused a statistically significant reduction in the percentage of motile spermatozoa starting at 4 days of storage (Table 1). A similar RSV effect was observed in the velocity parameters (Table 1) with a clear and statistically significant reduction in VCL (Table 1), VAP and VSL (data not shown) in spermatozoa stored in presence of 66 and $100 \mu \mathrm{M}$ of RSV.

Addition of RSV was without any effect in both the linearity of spermatozoa movement, as well as in the percentage of spermatozoa showing progressive movement at any dose or storage time (Table 2). 
Table 1. Spermatozoa motility parameters after addition of different resveratrol concentrations to boar semen doses preserved at $17^{\circ} \mathrm{C}$ for 7 days

\begin{tabular}{|c|c|c|c|c|c|c|c|c|}
\hline & \multicolumn{4}{|c|}{ MOTILE SPERMATOZOA (\%) } & \multicolumn{4}{|c|}{ CURVILINEAR VELOCITY $(\mu \mathrm{m} / \mathrm{s})$} \\
\hline & Day 0 & Day 1 & Day 4 & Day 7 & Day 0 & Day 1 & Day 4 & Day 7 \\
\hline BTS & & $91.0 \pm 1.7^{\mathrm{a}, 1}$ & $89.8 \pm 1.5^{\mathrm{ab}, 1}$ & $79.1 \pm 3.2^{\mathrm{b}, 1}$ & & $76.4 \pm 4.85^{\mathrm{a}, 1}$ & $78.1 \pm 4.2^{\mathrm{a}, 1}$ & $75.4 \pm 4.7^{\mathrm{a}, 1}$ \\
\hline RSV10 & & $91.0 \pm 2.4^{\mathrm{a}, 1}$ & $88.5 \pm 2.2^{\mathrm{ab}, 1}$ & $79.8 \pm 3.7^{\mathrm{b}, 1}$ & & $76.6 \pm 4.7^{\mathrm{a}, 1}$ & $72.2 \pm 4.1^{\mathrm{a}, 1}$ & $76.3 \pm 4.3^{\mathrm{a}, 1}$ \\
\hline RSV33 & $93.4 \pm 1.7^{\mathrm{a}}$ & $91.3 \pm 2.3^{\mathrm{a}, 1}$ & $86.3 \pm 2.0^{\mathrm{a}, 1}$ & $72.9 \pm 5.4^{\mathrm{b}, 1}$ & $74.6 \pm 5.4^{\mathrm{a}}$ & $78.3 \pm 4.7^{\mathrm{a}, 1}$ & $70.4 \pm 4.1^{\mathrm{a}, 1}$ & $65.6 \pm 4.6^{\mathrm{a}, 1,2}$ \\
\hline RSV66 & & $86.8 \pm 3.3^{\mathrm{a}, \mathrm{b}, 1}$ & $80.6 \pm 2.7^{\mathrm{b}, 1,2}$ & $60.4 \pm 6.1^{\mathrm{c}, 2}$ & & $76.9 \pm 3.7^{\mathrm{a}, 1}$ & $62.6 \pm 3.5^{\mathrm{a}, 1,2}$ & $53.5 \pm 3.9^{\mathrm{b}, 2,3}$ \\
\hline RSV100 & & $83.1 \pm 3.6^{\mathrm{a}, \mathrm{b}, 1}$ & $71.9 \pm 4.7^{\mathrm{b}, 2}$ & $51.2 \pm 5.7^{\mathrm{c}, 2}$ & & $64.3 \pm 3.6^{\mathrm{a}, 1}$ & $47.3 \pm 4.7^{\mathrm{b}, 2}$ & $44.3 \pm 3.2^{\mathrm{b}, 3}$ \\
\hline
\end{tabular}

Boar seminal doses were preserved at $17^{\circ} \mathrm{C}$ during 7 days in BTS in absence or presence of different concentrations of RSV $(10,33,66$ and $100 \mu \mathrm{M})$. Percentage of motile spermatozoa and curvilinear spermatozoa velocity (VCL in $\mu \mathrm{m} / \mathrm{s}$ ) were measured by CASA system (ISAS ${ }^{\circledR}$ ) as described in Materials and Methods. Results are expressed as mean \pm standard error of the mean (SEM) $(n=12)$. Within a parameter (column) or within a RSV concentration given (row), different superscripts $\left({ }^{\mathrm{a}, \mathrm{b}, \mathrm{c}}\right)$ mean statistical differences between days. Within a parameter and for a given day of preservation, differences between RSV concentrations are indicated by different numerical superscript $\left({ }^{1,2,3}\right)$.

Table 2. Spermatozoa motility parameters after addition of different resveratrol concentrations to boar semen doses preserved at $17^{\circ} \mathrm{C}$ for 7 days.

\begin{tabular}{|c|c|c|c|c|c|c|c|c|}
\hline & \multicolumn{4}{|c|}{ PROGRESSIVE MOTILITY (\%) } & \multicolumn{4}{|c|}{ LINEARITY INDEX (\%) } \\
\hline & Day 0 & Day 1 & Day 4 & Day 7 & Day 0 & Day 1 & Day 4 & Day 7 \\
\hline BTS & $52.8 \pm 3.4^{\mathrm{a}}$ & $55.5 \pm 3.0^{\mathrm{a}, 1}$ & $56.8 \pm 4.0^{\mathrm{a}, 1}$ & $47.6 \pm 3.3^{\mathrm{a}, 1}$ & $61.3 \pm 1.6^{\mathrm{a}}$ & $61.9 \pm 1.6^{\mathrm{a}, 1}$ & $61.8 \pm 2.0^{\mathrm{a}, 1}$ & $56.1 \pm 1.9^{\mathrm{a}, 1}$ \\
\hline RSV10 & & $58.1 \pm 2.9^{\mathrm{a}, 1}$ & $56.0 \pm 3.0^{\mathrm{a}, 1}$ & $48.8 \pm 3.4^{\mathrm{a}, 1}$ & & $62.8 \pm 1.5^{\mathrm{a}, 1}$ & $61.5 \pm 1.6^{\mathrm{a}, 1}$ & $56.7 \pm 1.8^{\mathrm{a}, 1}$ \\
\hline RSV33 & & $54.8 \pm 3.3^{\mathrm{a}, 1}$ & $58.1 \pm 3.6^{\mathrm{a}, 1}$ & $51.3 \pm 1.6^{\mathrm{a}, 1}$ & & $61.0 \pm 1.6^{\mathrm{a}, 1}$ & $61.3 \pm 2.0^{\mathrm{a}, 1}$ & $56.5 \pm 0.9^{\mathrm{a}, 1}$ \\
\hline RSV66 & & $54.5 \pm 3.1^{\mathrm{a}, 1}$ & $61.0 \pm 3.2^{\mathrm{a}, 1}$ & $51.2 \pm 1.8^{\mathrm{a}, 1}$ & & $59.0 \pm 1.7^{\mathrm{a}, \mathrm{b}, 1}$ & $60.9 \pm 1.8^{\mathrm{a}, 1}$ & $54.2 \pm 1.3^{\mathrm{b}, 1}$ \\
\hline RSV100 & & $58.6 \pm 2.0^{\mathrm{a}, 1}$ & $57.9 \pm 3.5^{\mathrm{a}, 1}$ & $48.2 \pm 1.6^{\mathrm{a}, 1}$ & & $60.0 \pm 1.3^{\mathrm{a}, 1}$ & $57.1 \pm 2.0^{\mathrm{a}, 1}$ & $51.0 \pm 1.1^{\mathrm{b}, 1}$ \\
\hline
\end{tabular}

Boar seminal doses were preserved at $17^{\circ} \mathrm{C}$ during 7 days in BTS in absence or presence of different concentrations of RSV $(10,33,66$ and $100 \mu \mathrm{M})$. Progressive motility and linearity index was measured by CASA system (ISAS ${ }^{\circledR}$ ) as described in Materials and Methods. Results are expressed as mean \pm standard error of the mean (SEM) $(n=12)$. Within a parameter (column) or within a RSV concentration given (row), different superscripts $\left({ }^{\mathrm{a}, \mathrm{b}, \mathrm{c}}\right)$ mean statistical differences between days. Within a parameter and for a given day of preservation, differences between RSV concentrations are indicated by different numerical superscript $\left(^{1,2,3}\right)$.

Table 3. Spermatozoa viability and the integrity of acrosome and plasma membranes after addition of different resveratrol concentrations to boar semen doses preserved at $17^{\circ} \mathrm{C}$ for 7 days

\begin{tabular}{|c|c|c|c|c|c|c|c|c|c|c|c|c|}
\hline & \multicolumn{4}{|c|}{ CELL VIABILITY (SYBR-14 ${ }^{+} /$PI) } & \multicolumn{4}{|c|}{ ACROSOME INTEGRITY (PNA $\left.{ }^{+} / \mathrm{PI}^{-}\right)$} & \multicolumn{4}{|c|}{$\begin{array}{l}\text { PLASMA MEMBRANE PHOSPHOLIPID } \\
\text { DISORDER }\left(\mathrm{M540}^{+} / \text {YOPRO }^{-}\right)\end{array}$} \\
\hline & Day 0 & Day 1 & Day 4 & Day 7 & Day 0 & Day 1 & Day 4 & Day 7 & Day 0 & Day 1 & Day 4 & Day 7 \\
\hline BTS & $93.4 \pm 1.7^{\mathrm{a}}$ & $92.6 \pm 0.5^{\mathrm{a}, 1}$ & $91.8 \pm 0.8^{\mathrm{a}, 1}$ & $89.2 \pm 1.3^{\mathrm{a}, 1}$ & $3.7 \pm 0.5^{\mathrm{a}}$ & $4.2 \pm 0.7^{\mathrm{a}, 1}$ & $4.9 \pm 0.8^{\mathrm{a}, 1}$ & $8.1 \pm 1.7^{\mathrm{a}, 1}$ & $8.6 \pm 0.8^{\mathrm{a}}$ & $8.8 \pm 0.6^{\mathrm{a}, 1}$ & $15.0 \pm 2.9^{\mathrm{a}, \mathrm{b}, 1}$ & $22.0 \pm 4.1^{\mathrm{b}, 1}$ \\
\hline RSV10 & & $91.5 \pm 0.6^{\mathrm{a}, 1}$ & $89.2 \pm 1.1^{\mathrm{a}, 1}$ & $88.7 \pm 0.8^{\mathrm{a}, 1}$ & & $4.0 \pm 0.5^{\mathrm{a}, 1}$ & $5.7 \pm 1.0^{\mathrm{a}, \mathrm{b}, 1}$ & $9.4 \pm 2.5^{b, 1}$ & & $10.5 \pm 0.7^{\mathrm{a}, 1}$ & $14.2 \pm 2.9^{\mathrm{a}, \mathrm{b}, 1}$ & $21.1 \pm 4.7^{\mathrm{b}, 1}$ \\
\hline RSV33 & & $91.7 \pm 0.5^{\mathrm{a}, 1}$ & $88.9 \pm 1.0^{\mathrm{a}, 1}$ & $88.8 \pm 0.8^{\mathrm{a}, 1}$ & & $4.0 \pm 0.5^{\mathrm{a}, 1}$ & $5.2 \pm 0.7^{\mathrm{a}, \mathrm{b}, 1}$ & $9.2 \pm 2.2^{b, 1}$ & & $10.1 \pm 0.8^{\mathrm{a}, 1}$ & $15.9 \pm 3.3^{\mathrm{a}, 1}$ & $25.9 \pm 5.8^{\mathrm{b}, 1}$ \\
\hline RSV66 & & $91.3 \pm 0.4^{\mathrm{a}, 1}$ & $89.5 \pm 1.0^{\mathrm{a}, 1}$ & $88.1 \pm 1.0^{\mathrm{a}, 1}$ & & $4.0 \pm 0.4^{\mathrm{a}, 1}$ & $5.6 \pm 0.8^{a, b, 1}$ & $10.8 \pm 2.7^{b, 1}$ & & $10.5 \pm 0.8^{\mathrm{a}, \mathrm{b}, 1}$ & $20.0 \pm 4.2^{\mathrm{b}, \mathrm{c}, 1}$ & $28.3 \pm 5.8^{\mathrm{c}, 1}$ \\
\hline RSV100 & & $91.5 \pm 0.7^{\mathrm{a}, 1}$ & $89.8 \pm 1.1^{\mathrm{a}, 1}$ & $86.1 \pm 1.7^{\mathrm{a}, 1}$ & & $4.2 \pm 0.7^{\mathrm{a}, 1}$ & $4.9 \pm 0.8^{\mathrm{a}, 1}$ & $12.3 \pm 2.9^{\mathrm{b}, 1}$ & & $9.9 \pm 0.8^{\mathrm{a}, 1}$ & $22.8 \pm 4.6^{\mathrm{b}, 1}$ & $41.6 \pm 6.1^{\mathrm{c}, 2}$ \\
\hline
\end{tabular}

Boar seminal doses were preserved at $17^{\circ} \mathrm{C}$ during 7 days in BTS in absence or presence of different concentrations of RSV $(10,33,66$ and $100 \mu \mathrm{M})$. Percentages of cell viability, plasma membrane phospholipid disorder and acrosomal integrity of spermatozoa were measured by flow cytometry as described in Materials and Methods. Results are expressed as mean \pm standard error of the mean (SEM) $(n=12)$. Within a RSV concentration given (row), differences between days for a given parameter (column) are indicated by different superscripts $\left({ }^{\mathrm{a}, \mathrm{b}, \mathrm{c}}\right)$. 
Within a parameter and for a given day of preservation (column), differences between RSV concentrations are indicated by different numerical superscript $\left({ }^{1,2,3}\right)$.

3.2 Effects of Resveratrol on the Viability, Plasma Membrane Phospholipid Disorder and Acrosome Membrane Integrity of Spermatozoa During Boar Semen Storage at $17^{\circ} \mathrm{C}$ in BTS

To evaluate the effect of RSV in spermatozoa viability, plasma membrane phospholipid disorder and acrosome membrane integrity during semen storage we used the experimental design 1 described in materials and methods.

The storage of boar semen in the presence of different doses of RSV $(10,33,66$ and $100 \mu \mathrm{M})$ did not affect either the percentage of viable spermatozoa with an intact plasma membrane or the percentage of spermatozoa presenting altered acrosomal membrane, compared with BTS alone at any storage time or dose (Table 3).

Only the highest doses of RSV used $(100 \mu \mathrm{M})$ caused a statistically significant increase in the percentage of spermatozoa showing a higher disorder on plasma membrane phospholipid on day 7 of semen storage (Table 3).

3.3 Calcium Influx and the Specific Response to Bicarbonate in Boar Semen Stored at $17^{\circ} \mathrm{C}$ in BTS in Presence of $R S V$

To evaluate the effect of RSV on calcium influx and the specific response of boar spermatozoa to bicarbonate, boar seminal doses were diluted in BTS without or with different concentrations of RSV ( 33 and $100 \mu \mathrm{M}$ ). At 1, 4 and 7 days of storage at $17^{\circ} \mathrm{C}$, specific response to bicarbonate upon exposure of spermatozoa to capacitating conditions was calculated as the difference in the responsiveness to incubation conditions in $\mathrm{TyrBicCa}(\Delta 60-3)$ and TyrCa $(\Delta 60-3)$. Only boar seminal doses incubated with the highest dose of RSV show a statically significant reduction in the specific response to bicarbonate after 7 days of storage at $17^{\circ} \mathrm{C}$, with a 3 -fold decrease compared with BTS alone (Table 4).

Table 4. Specific response to bicarbonate in boar semen doses supplemented with different resveratrol concentrations and preserved at $17^{\circ} \mathrm{C}$

\begin{tabular}{|c|c|c|c|c|c|c|}
\hline & \multicolumn{3}{|c|}{$\begin{array}{l}\text { SPECIFIC RESPONSE } \\
\text { BICARBONATE }\end{array}$} & \multicolumn{3}{|c|}{$\begin{array}{l}\text { DESTABILIZING EFFECT OF } \\
\text { EXTRACELLULAR CALCIUM }\end{array}$} \\
\hline & Day 1 & Day 4 & Day 7 & Day 1 & Day 4 & Day 7 \\
\hline BTS & $43.9 \pm 4.1^{\mathrm{a}, 1}$ & $33.0 \pm 4.2^{\mathrm{a}, 1}$ & $21.5 \pm 4.2^{b, 1}$ & $1.3 \pm 0.9^{\mathrm{a}, 1}$ & $3.7 \pm 1.4^{\mathrm{a}, 1}$ & $1.6 \pm 1.3^{\mathrm{a}, 1}$ \\
\hline RSV33 & $48.3 \pm 3.5^{\mathrm{a}, 1}$ & $39.7 \pm 2.2^{\mathrm{a}, 1}$ & $23.9 \pm 3.7^{\mathrm{b}, 1}$ & $3.8 \pm 1.7^{\mathrm{a}, 1}$ & $1.8 \pm 1.1^{\mathrm{a}, 1}$ & $3.5 \pm 2.9^{\mathrm{a}, 1}$ \\
\hline RSV100 & $44.3 \pm 6.4^{\mathrm{a}, 1}$ & $29.9 \pm 4.6^{\mathrm{a}, 1}$ & $6.8 \pm 5.2^{b, 2}$ & $2.0 \pm 1.2^{\mathrm{a}, 1}$ & $-0.1 \pm 0.5^{\mathrm{a}, 1}$ & $11.5 \pm 4.0^{\mathrm{b}, 2}$ \\
\hline
\end{tabular}

Responsiveness of spermatozoa was calculated as changes in the live, low- $\mathrm{Ca}^{2+}$ subpopulation (PI-negative/ Fluo-3-negative) at the beginning ( $3 \mathrm{~min})$ and after $60 \mathrm{~min}$ of incubation ( $\Delta=60 \mathrm{~min}-3 \mathrm{~min}$ ) in TyrBicCa, TyrCa or TyrControl. The specific response to bicarbonate describes the difference in the responsiveness in TyrBicCa and TyrCa. The destabilizing effect of extracellular calcium was calculated as the difference in the responsiveness in TyrCa and TyrControl. Results are mean \pm standard error of the mean (SEM) $(n=8)$. Within a treatment (row), differences between days for a given spermatozoa response (column) are indicated by different superscripts $\left({ }^{\mathrm{a}, \mathrm{b}}\right)$. Within a given time (column), differences between RSV concentrations are indicated by different numerical superscript $\left({ }^{1,2}\right)$.

In addition, the destabilizing effect that can be attributed to the presence of extracellular calcium was monitored as the difference in the responsiveness to incubation conditions in TyrCa and TyrControl. After 7 days storage at $17^{\circ} \mathrm{C}$, seminal doses stored in presence of RSV $100 \mu \mathrm{M}$ showed a statistically significant increase in the amount of spermatozoa that destabilized due to the presence of extracellular calcium. Values were 7-fold higher when compared with BTS alone (Table 4).

3.4 Effects of Resveratrol on Mitochondrial Membrane Potential and ATP Content of Boar Semen Preserved at $17^{\circ} \mathrm{C}$ in $B T S$

To evaluate the effect of RSV on mitochondrial membrane potential during semen storage, boar seminal doses were diluted in BTS without or with different concentrations of RSV (10,33, 66 and $100 \mu \mathrm{M}$; experiment 1$)$. After BTS dilution (day 0 ) and after 1,4 and 7 days of semen storage at $17^{\circ} \mathrm{C}$, mitochondrial membrane potential of spermatozoa was evaluated. Supplementation with any dose of RSV causes a significant decrease in the percentage 
of spermatozoa displaying high MMP at any time of semen storage (Table 5), showing the higher and statistically significant effect at 1 -day storage at $17^{\circ} \mathrm{C}$ for any dose of RSV use (Table 5).

Table 5. Mitochondrial membrane potential after addition of different resveratrol concentrations to boar semen doses preserved at $17^{\circ} \mathrm{C}$ for 7 days

\begin{tabular}{lllll}
\hline & \multicolumn{4}{c}{ HIGH MITOCHONDRIAL MEMBRANE POTENTIAL (\%) } \\
\cline { 2 - 5 } & Day 0 & Day 1 & Day 4 & Day 7 \\
\hline BTS & $73.5 \pm 2.6^{\mathrm{a}}$ & $65.8 \pm 3.9^{\mathrm{a}, 1}$ & $76.4 \pm 2.8^{\mathrm{a}, 1}$ & $76.2 \pm 4.2^{\mathrm{a}, 1}$ \\
RSV10 & $35.7 \pm 8.7^{\mathrm{b}, 2}$ & $40.4 \pm 11.1^{\mathrm{a}, 1}$ & $44.9 \pm 10.5^{\mathrm{a}, 2}$ \\
RSV33 & $38.3 \pm 8.0^{\mathrm{b}, \mathrm{c}, 1,2}$ & $52,2 \pm 6.8^{\mathrm{a}, \mathrm{c}, 1}$ & $50.0 \pm 9.0^{\mathrm{a}, \mathrm{b}, 1,2}$ \\
RSV66 & $32.4 \pm 8.7^{\mathrm{b}, 2}$ & $55.5 \pm 6.1^{\mathrm{a}, \mathrm{b}, 1}$ & $59.3 \pm 6.1^{\mathrm{a}, \mathrm{b}, 1,2}$ \\
RSV100 & $31.7 \pm 8.1^{\mathrm{b}, \mathrm{c}, 2}$ & $50.1 \pm 8.1^{\mathrm{a}, \mathrm{c}, 1}$ & $62.0 \pm 6.0^{\mathrm{a}, 1,2}$
\end{tabular}

Boar seminal doses were preserved at $17^{\circ} \mathrm{C}$ during 7 days in BTS in absence or presence of different concentrations of RSV $(10,33,66$ and $100 \mu \mathrm{M})$. Percentage of spermatozoa with high mitochondrial membrane potential was measured by flow cytometry as described in Materials and Methods. Results are expressed as mean \pm standard error of the mean (SEM) $(n=12)$. Within a treatment (row), differences between days (column) are indicated by different superscripts $\left({ }^{\mathrm{a}, \mathrm{b}, \mathrm{c}}\right)$. Within a given time (column), differences between RSV concentrations are indicated by different numerical superscript $\left({ }^{1,2,3}\right)$.

To evaluate the effect of RSV on ATP content during semen storage, boar seminal doses were diluted in BTS without or with different concentrations of RSV (33 and $100 \mu \mathrm{M}$; experiment 2 ). ATP content was determined directly from the stored samples $\left(17^{\circ} \mathrm{C}\right)$ and after 40 min incubation at $38.5^{\circ} \mathrm{C}$ under $5 \% \mathrm{CO}_{2}$ atmosphere to activate spermatozoa. Compared with BTS alone, both concentrations of RSV (33 and $100 \mu \mathrm{M})$ caused a clear and statistically significant decrease in the ATP content of spermatozoa at any time storage. The decrease in ATP content was present under unstimulated and stimulated conditions (Table 6). Analysis of data showed a statistically significant negative correlation between ATP concentration of spermatozoa and the dose of RSV used $(\mathrm{r}=-0.767, \mathrm{p}<0.01)$. Moreover, further analysis of data from semen stored at $17^{\circ} \mathrm{C}$ showed a significant positive correlation between the spermatozoa ATP content (Table 6) and the percentage of motile spermatozoa $(\mathrm{r}=0.463$; $\mathrm{p}<0.01)$, VCL $(\mathrm{r}=0.380 ; \mathrm{p}<0.01)$, VAP $(\mathrm{r}=0.489 ; \mathrm{p}<0.01)$ and $\operatorname{VSL}(\mathrm{r}=0.557 ; \mathrm{p}<0.01)$.

Table 6. ATP levels in spermatozoa of boar semen doses supplemented with different resveratrol concentrations and preserved at $17^{\circ} \mathrm{C}$

\begin{tabular}{|c|c|c|c|c|}
\hline & \multicolumn{3}{|c|}{ ATP Content (pmol/10 ${ }^{6}$ spermatozoa) } & \multirow[b]{2}{*}{ Day 7} \\
\hline & & Day 1 & Day 4 & \\
\hline \multirow{3}{*}{$\begin{array}{l}17^{\circ} \mathrm{C} \\
\text { (Unstimulated) }\end{array}$} & BTS & $119.0 \pm 21.4^{\mathrm{a}, 1}$ & $138.0 \pm 13.4^{\mathrm{a}, 1^{*}}$ & $107.2 \pm 13.1^{\mathrm{a}, 1}$ \\
\hline & RSV33 & $22.9 \pm 5.0^{\mathrm{a}, 2}$ & $49.3 \pm 13.3^{\mathrm{a}, 2^{*}}$ & $34.0 \pm 5.0^{\mathrm{a}, 2}$ \\
\hline & RSV100 & $8.2 \pm 1.9^{\mathrm{a}, 2}$ & $8.7 \pm 2.3^{\mathrm{a}, 3}$ & $9.5 \pm 2.7^{\mathrm{a}, 2}$ \\
\hline \multirow{3}{*}{$\begin{array}{l}40 \mathrm{~min}, 38.5^{\circ} \mathrm{C}, 5 \% \mathrm{CO}_{2} \\
\text { (Stimulated) }\end{array}$} & BTS & $104.6 \pm 17.2^{\mathrm{a}, 1}$ & $94.4 \pm 18.6^{\mathrm{a}, 1^{*}}$ & $98.7 \pm 17.0^{\mathrm{a}, 1}$ \\
\hline & RSV33 & $20.8 \pm 3.8^{\mathrm{a}, 2}$ & $19.8 \pm 3.8^{\mathrm{a}, 2^{*}}$ & $26.2 \pm 5.1^{\mathrm{a}, 2}$ \\
\hline & RSV100 & $6.9 \pm 1.8^{\mathrm{a}, 2}$ & $7.3 \pm 2.2^{\mathrm{a}, 2}$ & $4.5 \pm 2.1^{\mathrm{a}, 2}$ \\
\hline
\end{tabular}

Boar seminal doses were preserved at $17^{\circ} \mathrm{C}$ during 7 days in BTS in absence or presence of different concentrations of RSV (33 and $100 \mu \mathrm{M})$. Spermatozoa ATP content was measured as described in Materials and Methods. Results are expressed as mean \pm standard error of the mean (SEM) $(n=6)$. Within a RSV concentration (row), different superscripts $\left({ }^{\mathrm{a}, \mathrm{b}, \mathrm{c}}\right)$ indicate statistical differences between days. Within a preservation day (column) differences between RSV concentrations are indicated by different numerical superscript $\left({ }^{1,2}\right)$. Within a day of preservation and treatment, differences between unstimulated and stimulated are indicated as $\left(^{*}\right)$. 


\section{Discussion}

At present, a large number of studies show that the natural polyphenol resveratrol may be beneficial to many aspects of cell function and animal health; however, this compound displays a dichotomy: low doses can improve cell function while high doses increase cell death with a concomitant decrease in the mitochondrial membrane function (Fulda et al., 2010; Low et al., 2010; Pervaiz \& Holme, 2009; Sareen et al., 2006; Zini et al., 1999; Zunino \& Storms, 2006). Regarding male reproductive system, some studies have focused in the actions of resveratrol with divergent results (Branco et al., 2010; Collodel et al., 2011; Garcez et al., 2010; Juan et al., 2005; Ourique et al., 2013; Silva et al., 2012).

In the present study, results obtained with conventional parameters to determine the quality of boar semen doses do not allow to respond to the question of whether RSV addition improves preservation of semen doses stored at $17^{\circ} \mathrm{C}$ or whether has an adverse effect. 1) Our data do not show any adverse effect of RSV on the plasma membrane integrity (viability) of boar spermatozoa preserved in seminal doses in BTS at $17^{\circ} \mathrm{C}$ with no cytotoxic activity at any dose or time evaluated; thus boar spermatozoa are less sensitive to the possible harmful of RSV than swim-up selected human spermatozoa where treatment with $100 \mu \mathrm{M}$ RSV caused almost a $100 \%$ of spermatozoa death (Collodel et al., 2011); 2) Moreover, our study shows that supplementation of boar semen with high doses of RSV causes a small decrease in the percentage of total motile spermatozoa as well as in spermatozoa velocities after 4 and 7 days storage whereas low doses of RSV are without any effect on sperm motility parameters. Similar results were obtained in swim-up selected human spermatozoa where high doses of RSV were able to inhibit progressive motility whereas low doses of RSV cause high values of progressive motility (Collodel et al., 2011); however, the addition of RSV before ram sperm cryopreservation was without effect on progressive motility (Silva et al., 2012), whereas addition of RSV to ram spermatozoa kept at $5^{\circ} \mathrm{C}$ for 9 days induced a significant lower reduction in spermatozoa motility (Sarlos et al., 2002); 3) Regarding RSV effect in the plasma membrane phospholipid disorder and acrosomal membrane integrity during boar semen storage, results obtained are similar to those in sperm motility. Whereas high doses of RSV show a slight negative effect in the percentage of spermatozoa showing high plasma membrane phospholipid disorder after 7 days liquid storage, however, RSV doses of 10-66 $\mu \mathrm{M} \mu \mathrm{M}$ are without any effect in these parameters. In the case of ram semen cryopreserved with RSV there were no differences among different doses (from 5 to $20 \mu \mathrm{g} / \mathrm{mL}$ ) with regards both plasma membrane or acrosome integrity (Silva et al., 2012) or even a decrease was observed in the percentage of ram spermatozoa with acrosomal damage after long term storage at $5^{\circ} \mathrm{C}$ (Sarlos et al., 2002). In summary, the use of conventional sperm parameters to test the quality of boar semen doses incubated in presence of RSV does not allow us to point to a potential beneficial effect of this polyphenol in the cellular function of spermatozoa during boar semen storage at $17^{\circ} \mathrm{C}$.

Contradictory results with RSV supplementation could be attributed to RSV action being affected by several factors including animal species under study, extender medium used or to the treatment of sperm samples (cryopreservation, swim-up or refrigerated storage). Moreover, conventional sperm parameters used to test the quality of boar semen doses mostly are too insensitive to assess the fertilization potential of liquid stored semen (Waberski et al., 2011). In recent studies, effort has been focused to test whether spermatozoa membranes retain their ability to respond to oviductal signals, considering dynamic responses in spermatozoa under experimentally mimicked fertilizing conditions (Henning et al., 2012; Petrunkina et al., 2005a). Several studies have indicated that a certain subpopulation of boar spermatozoa may loose their responsiveness to the capacitating stimulus bicarbonate during hypothermic storage (Green \& Watson, 2001; Guthrie \& Welch, 2005; Harrison et al., 1996; Petrunkina et al., 2005b). Henning et al. (2012) showed that the comparison of calcium-dependent spermatozoa responses between three different media, capacitating Tyrode's medium, (including calcium and bicarbonate), bicarbonate-free Tyrode's medium and calcium- and bicarbonate-free medium, sensitively detected storage-related changes in the spermatozoa population. Our results show that previous incubation in the presence of RSV $33 \mu \mathrm{M}$ is unable to revert the decline in the response to bicarbonate and therefore the increasing inherent instability brought about by liquid storage time of boar semen. Moreover, conservation of seminal doses in the presence of RSV $100 \mu \mathrm{M}$ induces a significant higher reduction in the response to bicarbonate together with a significant increase in the response to calcium in extended boar semen stored at $17^{\circ} \mathrm{C}$. As calcium is a source of cell instability this loss in the calcium homeostasis is proposed to be the best parameter to assess the destabilization of spermatozoa membrane (Henning et al., 2012). Our results show that addition of RSV to extended boar semen stored at $17^{\circ} \mathrm{C}$ induces a higher loss of calcium homeostasis related with a greater membrane destabilization which compromises capacitation dynamics and thereby the chances of fertilization.

Our more evident result is likely the diminution of mitochondrial membrane potential observed in spermatozoa treated with any concentration of RSV $(10-100 \mu \mathrm{M})$. Similar results were obtained in frozen-thawed ram spermatozoa showing the control group a higher proportion of spermatozoa with high mitochondrial membrane 
potential than in RSV $20 \mu \mathrm{g} / \mathrm{mL}$ treated group (Silva et al., 2012). The decrease in the mitochondrial membrane potential caused by RSV has been widely described in somatic cells and has allowed its use in cancer treatment since RSV is able i) to regulate the mitochondrial permeability transition pore (Zunino \& Storms, 2006), ii) to increase the mitochondrial superoxide production (Low et al., 2010), iii) to decrease the mitochondrial membrane potential (Sareen et al., 2006; van Ginkel et al., 2007) and iv) to disrupt the mitochondrial respiratory chain (Zheng \& Ramirez, 2000; Zini et al., 1999). The ATP content diminution in RSV treated boar spermatozoa is very clear in our study, falling between 3-6 times when using $33 \mu \mathrm{M}$ RSV and 10 to 20 times when using $100 \mu \mathrm{M}$ RSV. Spermatozoa movement requires ATP hydrolysis catalysed by dynein ATPases localized at the axoneme (Tash 1989). The amount of ATP in non-treated samples does not vary along the time of preservation ( $p>0.05)$, which is in agreement with previous results from Long and Guthrie (2006) in boar seminal doses, although our values are slightly higher. We have obtained much lower values of ATP in spermatozoa treated with 33 and $100 \mu \mathrm{M}$ RSV compared with control spermatozoa at any time of preservation, which can be the cause for a parallel decrease in sperm motility. Positive correlations were found between the amount of ATP and the percentage of motile spermatozoa in the RSV treated samples compared to control. This finding confirms the work of Gogol et al. (2009) demonstrating that when ATP levels of boar seminal doses decreases, the percentage of motile spermatozoa also decrease. In addition, we have found a significant correlation between spermatozoa ATP level and velocities that may explain why those spermatozoa from seminal doses treated with RSV that contain lower amount of ATP than control (BTS), move with lower velocities.

\section{Conclusions}

Besides its possible negative effect in spermatozoa function, addition of RSV has been recommended in human sperm prior ICSI because it reduces sperm DNA damage during the process of cryopreservation (Branco et al., 2010), prevents lipid damage induced by cryopreservation (Garcez et al., 2010) and is able to protect sperm against oxidative stress (Collodel et al., 2011). However, in boar spermatozoa, the loss in specific reactivity to capacitating stimuli together with the fall in ATP content, the mitochondrial membrane potential reduction, the increase of plasma membrane phospholipid disorder and the lower percentage of motile spermatozoa lead us to assume that RSV treated samples could be considered subfertile compared with semen stored hypothermically in the standard extender BTS. Our results do not support the use of RSV as a potential supplement to improve the quality of extended boar semen during storage at $17^{\circ} \mathrm{C}$.

\section{Acknowledgments}

This work was supported by National Grant AGL2010-15188 (from the Spanish Ministry of Education and Science) and regional Grant PRI09A077 and GR10156 (from Government of Extremadura, Spain). Martin-Hidalgo D. received a Ph D fellowship award from the Government of Extremadura-European Social Fund, Spain.

\section{References}

Awda, B. J., Mackenzie-Bell, M., \& Buhr, M. M. (2009). Reactive oxygen species and boar sperm function. Biol. Reprod, 81(3), 553-561. http://dx.doi.org/10.1095/biolreprod.109.076471

Branco, C. S., Garcez, M. E., Pasqualotto, F. F., Erdtman, B., \& Salvador, M. (2010). Resveratrol and ascorbic acid prevent DNA damage induced by cryopreservation in human semen. Cryobiology, 60(2), 235-237. http://dx.doi.org/10.1016/j.cryobiol.2009.10.012

Cerolini, S., Maldjian, A., Surai, P., \& Noble, R. (2000). Viability, susceptibility to peroxidation and fatty acid composition of boar semen during liquid storage. Anim Reprod. Sci., 58(1-2), 99-111. http://dx.doi.org/10.1016/S0378-4320(99)00035-4

Collodel, G., Federico, M. G., Geminiani, M., Martini, S., Bonechi, C., Rossi, C., Figura, N., \& Moretti, E. (2011). Effect of trans-resveratrol on induced oxidative stress in human sperm and in rat germinal cells. Reprod. Toxicol., 31(2), 239-246. http://dx.doi.org/10.1016/j.reprotox.2010.11.010

Fulda, S., Galluzzi, L., \& Kroemer, G. (2010). Targeting mitochondria for cancer therapy. Nat. Rev. Drug Discov., 9(6), 447-464. http://dx.doi.org/10.1038/nrd3137

Funahashi, H., \& Sano, T. (2005). Select antioxidants improve the function of extended boar semen stored at 10 degrees C. Theriogenology, 63(6), 1605-1616. http://dx.doi.org/10.1016/j.theriogenology.2004.06.016

Gadea, J. (2003). Review: Semen extenders used in the artificial insemination of swine. Span J Agric Res, 1, 17-27. 
Garcez, M. E., Dos Santos, B. C., Lara, L. V., Pasqualotto, F. F., \& Salvador, M. (2010). Effects of resveratrol supplementation on cryopreservation medium of human semen. Fertil. Steril., 94(6), 2118-2121. http://dx.doi.org/10.1016/j.fertnstert.2010.01.058

Gogol, P., Szczesniak-Fabianczyk, B., \& Wierzchos-Hilczer, A. (2009). The photon emission, ATP level and motility of boar spermatozoa during liquid storage. Reprod. Biol., 9(1), 39-49. http://dx.doi.org/10.1016/S1642-431X(12)60093-X

Green, C. E., \& Watson, P. F. (2001). Comparison of the capacitation-like state of cooled boar spermatozoa with true capacitation. Reproduction, 122(6), 889-898. http://dx.doi.org/10.1530/rep.0.1220889

Guthrie, H. D., \& Welch, G. R. (2005). Effects of hypothermic liquid storage and cryopreservation on basal and induced plasma membrane phospholipid disorder and acrosome exocytosis in boar spermatozoa. Reprod. Fertil. Dev., 17(4), 467-477. http://dx.doi.org/10.1071/RD05003

Harrison, R. A., Ashworth, P. J., \& Miller, N. G. (1996). Bicarbonate/CO2, an effector of capacitation, induces a rapid and reversible change in the lipid architecture of boar sperm plasma membranes. Mol. Reprod. Dev., 45(3), 378-391. http://dx.doi.org/10.1002/(SICI)1098-2795(199611)45:3<378::AID-MRD16>3.0.CO;2-V

Harrison, R. A., Mairet, B., \& Miller, N. G. (1993). Flow cytometric studies of bicarbonate-mediated Ca2+ influx in boar sperm populations. Mol. Reprod. Dev., 35(2), 197-208. http://dx.doi.org/10.1002/mrd.1080350214

Henning, H., Petrunkina, A. M., Harrison, R. A., \& Waberski, D. (2012). Bivalent response to long-term storage in liquid-preserved boar semen: a flow cytometric analysis. Cytometry $A, \quad 81(7), \quad 576-587$. http://dx.doi.org/10.1002/cyto.a.22058

Johnson, L. A., Weitze, K. F., Fiser, P., \& Maxwell, W. M. (2000). Storage of boar semen. Anim Reprod. Sci., 62(1-3), 143-172. http://dx.doi.org/10.1016/S0378-4320(00)00157-3

Juan, M. E., Gonzalez-Pons, E., Munuera, T., Ballester, J., Rodriguez-Gil, J. E., \& Planas, J. M. (2005). trans-Resveratrol, a natural antioxidant from grapes, increases sperm output in healthy rats. J. Nutr., 135(4), 757-760.

Lee, K. W., \& Lee, H. J. (2006). The roles of polyphenols in cancer chemoprevention. Biofactors, 26(2), $105-121$. http://dx.doi.org/10.1002/biof.5520260202

Long, J. A., \& Guthrie, H. D. (2006). Validation of a rapid, large-scale assay to quantify ATP concentration in spermatozoa. Theriogenology, 65(8), 1620-1630. http://dx.doi.org/10.1016/j.theriogenology.2005.06.020

Low, I. C., Chen, Z. X., \& Pervaiz, S. (2010). Bcl-2 modulates resveratrol-induced ROS production by regulating mitochondrial respiration in tumor cells. Antioxid. Redox. Signal., 13(6), 807-819. http://dx.doi.org/10.1089/ars.2009.3050

Martin-Hidalgo, D., Baron, F. J., Bragado, M. J., Carmona, P., Robina, A., Garcia-Marin, L. J., \& Gil, M. C. (2011). The effect of melatonin on the quality of extended boar semen after long-term storage at 17 degrees $\mathrm{C}$. Theriogenology, 75(8), 1550-1560. http://dx.doi.org/10.1016/j.theriogenology.2010.12.021

Ourique, G. M., Finamor, I. A., Saccol, E. M., Riffel, A. P., Pes, T. S., Gutierrez, K., ... Barreto, K. P. (2013). Resveratrol improves sperm motility, prevents lipid peroxidation and enhances antioxidant defences in the testes of hyperthyroid rats. Reprod. Toxicol., 37, 31-39. http://dx.doi.org/10.1016/j.reprotox.2013.01.006

Pervaiz, S., \& Holme, A. L. (2009). Resveratrol: its biologic targets and functional activity. Antioxid. Redox. Signal., 11(11), 2851-2897. http://dx.doi.org/10.1089/ars.2008.2412

Petrunkina, A. M., Volker, G., Brandt, H., Topfer-Petersen, E., \& Waberski, D. (2005a). Functional significance of responsiveness to capacitating conditions in boar spermatozoa. Theriogenology, 64(8), 1766-1782. http://dx.doi.org/10.1016/j.theriogenology.2005.04.007

Petrunkina, A. M., Volker, G., Weitze, K. F., Beyerbach, M., Topfer-Petersen, E., \& Waberski, D. (2005b). Detection of cooling-induced membrane changes in the response of boar sperm to capacitating conditions. Theriogenology, 63(8), 2278-2299. http://dx.doi.org/10.1016/j.theriogenology.2004.10.008

Pursel, V. G., \& Johnson, L. A. (1975). Freezing of boar spermatozoa: fertilizing capacity with concentrated semen and a new thawing procedure. J. Anim Sci., 40(1), 99-102.

Pursel, V. G., Schulman, L. L., \& Johnson, L. A. (1978). Effect of Orvus ES Paste on acrosome morphology, motility and fertilizing capacity of frozen-thawed boar sperm. J. Anim Sci., 47(1), 198-202. 
Roca, J., Rodriguez, M. J., Gil, M. A., Carvajal, G., Garcia, E. M., Cuello, C., Vazquez, J. M., \& Martinez, E. A. (2005). Survival and in vitro fertility of boar spermatozoa frozen in the presence of superoxide dismutase and/or catalase. J. Androl, 26(1), 15-24.

Sareen, D., Van Ginkel, P. R., Takach, J. C., Mohiuddin, A., Darjatmoko, S. R., Albert, D. M., \& Polans, A. S. (2006). Mitochondria as the primary target of resveratrol-induced apoptosis in human retinoblastoma cells. Invest Ophthalmol. Vis. Sci., 47(9), 3708-3716. http://dx.doi.org/10.1167/iovs.06-0119

Sarlos, P., Molnar, A., Kokai, M., Gabor, G., \& Ratky, J. (2002). Comparative evaluation of the effect of antioxidants in the conservation of ram semen. Acta Vet. Hung., 50(2), 235-245. http://dx.doi.org/10.1556/AVet.50.2002.2.13

Schmid, S., Henning, H., Oldenhof, H., Wolkers, W. F., Petrunkina, A. M., \& Waberski, D. (2013). The specific response to capacitating stimuli is a sensitive indicator of chilling injury in hypothermically stored boar spermatozoa. Andrology, 1(3), 376-386. http://dx.doi.org/10.1111/j.2047-2927.2013.00045.x

Silva, E. C., Cajueiro, J. F., Silva, S. V., Soares, P. C., \& Guerra, M. M. (2012). Effect of antioxidants resveratrol and quercetin on in vitro evaluation of frozen ram sperm. Theriogenology, 77(8), 1722-1726. http://dx.doi.org/10.1016/j.theriogenology.2011.11.023

Tash, J. S. (1989). Protein phosphorylation: the second messenger signal transducer of flagellar motility. Cell Motil. Cytoskeleton, 14(3), 332-339. http://dx.doi.org/10.1002/cm.970140303

Van Ginkel, P. R., Sareen, D., Subramanian, L., Walker, Q., Darjatmoko, S. R., Lindstrom, M. J., ... Polans, A. S. (2007). Resveratrol inhibits tumor growth of human neuroblastoma and mediates apoptosis by directly targeting mitochondria. Clin. Cancer Res., 13(17), 5162-5169. http://dx.doi.org/10.1158/1078-0432.CCR-07-0347

Waberski, D., Schapmann, E., Henning, H., Riesenbeck, A., \& Brandt, H. (2011). Sperm chromatin structural integrity in normospermic boars is not related to semen storage and fertility after routine AI. Theriogenology, 75(2), 337-345. http://dx.doi.org/10.1016/j.theriogenology.2010.09.004

Waterhouse, K. E., De Angelis, P. M., Haugan, T., Paulenz, H., Hofmo, P. O., \& Farstad, W. (2004). Effects of in vitro storage time and semen-extender on membrane quality of boar sperm assessed by flow cytometry. Theriogenology, 62(9), 1638-1651. http://dx.doi.org/10.1016/j.theriogenology.2004.03.001

Zheng, J., \& Ramirez, V. D. (2000). Inhibition of mitochondrial proton F0F1-ATPase/ATP synthase by $\begin{array}{lllll}\text { polyphenolic phytochemicals. } B r . & J . & \text { Pharmacol, } & 130(5), & 1115-1123 .\end{array}$ http://dx.doi.org/10.1038/sj.bjp.0703397

Zini, R., Morin, C., Bertelli, A., Bertelli, A. A., \& Tillement, J. P. (1999). Effects of resveratrol on the rat brain respiratory chain. Drugs Exp. Clin. Res., 25(2-3), 87-97.

Zunino, S. J., \& Storms, D. H. (2006). Resveratrol-induced apoptosis is enhanced in acute lymphoblastic leukemia cells by modulation of the mitochondrial permeability transition pore. Cancer Lett., 240(1), 123-134. http://dx.doi.org/10.1016/j.canlet.2005.09.001

\section{Copyrights}

Copyright for this article is retained by the author(s), with first publication rights granted to the journal.

This is an open-access article distributed under the terms and conditions of the Creative Commons Attribution license (http://creativecommons.org/licenses/by/3.0/). 